\title{
Chemical Synthesis of Copper Nanoparticles
}

\author{
HAMID REZA GHORBANI* \\ Department of Chemical engineering, Qaemshahr Branch, Islamic Azad University, Qaemshahr, Iran \\ ${ }^{*}$ Corresponding author E-mail: hamidghorbani6@gmail.com \\ http://dx.doi.org/10.13005/ojc/300254
}

(Received: April 12, 2014; Accepted: May 24, 2014)

\begin{abstract}
ABSRTACT
Metal nanoparticles have attracted considerable interest particularly because of the size dependence of physical and chemical properties and its enormous technological potential. Among different metal nanoparticles, copper nanoparticles have attracted great attention because copper is one of the most key metals in new technology. Chemical methods are used to synthesize copper nanoparticles and among them chemical reduction is the most frequently applied method for the preparation of stable, colloidal dispersions in organic solvents. In this paper, a brief overview of the current research worldwide in the chemical synthesis of copper nanoparticles is discussed.
\end{abstract}

Key words: Copper Nanoparticles, Synthesis, Chemical Reduction, Photochemical, Electrochemical, Thermal Decomposition.

\section{INTRODUCTION}

Copper nanoparticles have great interest due to their optical, catalytic, mechanical and electrical properties. Copper is a good alternative material for noble metals such as Au and $\mathrm{Ag}$ as it is highly conductive and much more economical than them ${ }^{1,2}$. Copper plays an important role in electronic circuits because of its excellent electrical conductivity. Copper nanoparticles are inexpensive and their properties can be controlled depending on the synthesis method. Also in catalyst, the nanoparticles have a higher efficiency than particles $^{3,4,5}$. Copper nanoparticles are synthesized through different techniques. The most important methods for the synthesis of copper nanoparticles are chemical methods such as chemical reduction, electrochemical techniques, photochemical reduction and thermal decomposition. Copper nanoparticles can easily oxidize to form copper oxide. To avoid oxidation, these methods were usually performed in non-aqueous media, at low precursor concentration, and under an inert atmosphere (argon, nitrogen) ${ }^{6-10}$. In this paper, we reported the methods of chemical synthesis of copper nanoparticles and their characterization.

\section{Copper nanoparticles synthesis Chemical reduction}

One of the most important methods for the synthesis of copper nanoparticles is the reduction chemical method. In this technique a copper salt is reduced by a reducing agent such as polyols, sodium borohydride, Hydrazine, Ascorbic acid, hypophosphite ${ }^{11-15}$. In addition, it is used from capping agents such as Polyethylene glycol and 
poly (vinylpyrrolidone) ${ }^{16,17}$. Some of the chemical reducing reactions can be carried out at room temperature. Salzemann et al., used microemulsion method to synthesize nanoparticles of copper with size of $3-13 \mathrm{~nm}^{18}$. Copper nanoparticles were produced by the polyol method in ambient atmosphere. The obtained nanoparticles were confirmed by XRD to be crystalline copper. SEM study shows that sizes of particles produced were $48 \pm 8 \mathrm{~nm}^{17}$. Colloidal copper with particle sizes of 40-80 nm has been reported from reduction with sodium borohydride in aqueous solution at room temperature. The copper nanoparticles were stabilized by starch ${ }^{19}$. In 2008, copper nanoparticles were synthesized by the reduction of $\mathrm{Cu}^{2+}$ in solutions of poly(acrylic acid)-pluronic blends results in a stable sol of metallic copper with a particle size below $10 \mathrm{~nm}^{20}$. Reduction of copper ions by sodium borohydride in the presence of sodium polyacrylate was reported. Copper nanocrystals sizes were $14 \mathrm{~nm}^{21}$. Chatterjee et al. presented a simple method for synthesis of metallic copper nanoparticles using Cucl2 as reducing agent and gelatin as stabilizer with a size of $50-60 \mathrm{~nm}^{22}$. One of the chemical reduction methods is microemulsion technique. Microemulsions are isotropic, macroscopically homogeneous, and thermodynamically stable solutions containing at least three components, namely a polar phase (usually water), a nonpolar phase (usually oil) and a surfactant [23]. Copper nanoparticles synthesis was achieved by reduction of aqueous copper chloride solution using $\mathrm{NaBH}_{4}$ in the nonionic waterin-oil (w/o) microemulsions ${ }^{24}$. Solanki et al. reported synthesis of copper sulphide and copper nanoparticles with microemulsion method. XRD analysis of nanoparticles confirmed presence of metallic copper ${ }^{25}$. In 2013, facile synthesis of sizetunable copper and copper oxide nanoparticles was presented by Kumar et al. They found that reduction with hydrazine hydrate in an inert $\mathrm{N}_{2}$ environment gives copper nanoparticles whereas reaction with sodium borohydrate in aerobic condition gives copper(II) oxide nanoparticles ${ }^{26}$. In another study, copper salt was dissolved in dioxane/-AOT solution and reduced by hydrazine hydrate under vigorous stirring. Nanocolloids sizes were $70-80 \mathrm{~nm}^{27}$.

\section{Photochemical Method (Irradiation)}

Another chemical method

photochemical method. In this technique, the system is excited by radiation and thus it is produced active reducing agent such as radicals, electrons and excited components. This method has an important advantage compared to chemical reduction and it is removing impurities at low temperature. It is often used for the synthesis of noble metals. In this technique, it was prepared the desired salt solution with water or alcohols or organic solutions. Then the solution put under the radiation. In these conditions, electrons are released and metal is reduced.

In 2003, copper nanoparticles were synthesized by a single photochemical route ${ }^{28}$. Kapoor et al. reported photochemical formation of copper nanoparticles in poly ( $\mathrm{N}$-vinylpyrrolidone). They showed average particle size for $\mathrm{Cu}$ was 15 $\mathrm{nm}^{29}$. Zhu et al., have synthesized copper nanoparticles using copper sulfate as a precursor and sodium hypophosphite as reducing agent in ethylene glycol under microwave irradiation. The size of copper nanoparticles prepared by this method was $10 \mathrm{~nm}^{15}$. In another work, the effect of the presence of poly (vinyl pyrrolidone) (PVP) on the copper nanoparticle formation, obtained by UV irradiation of ethanol solution of $\mathrm{Cu}(\mathrm{acac})_{2}$ was investigated. It was found the advantages of the PVP use in the nanoparticle copper formation through the photochemical technique such as the exclusive formation of colloidal copper, their size control, stable colloidal solution and complete return to the starting complex ${ }^{30}$. In 2012, Zhu et al. reported a facile method for preparing copper nanoparticles and patterned surfaces with copper stripes by ultraviolet (UV) irradiation of a mixture solution containing a photoinitiator and a copper-amine coordination compound. They also studied the mechanism of photoreduction by UV-vis spectroscopy and gas chromatography-mass spectrometry ${ }^{31}$.

\section{Electrochemical Method (Electrolysis)}

Since long, electrolysis process was used to reduce of metal ions. Yang et al. reported synthesis of copper nanorods using electrochemical method. The mean diameter of a copper nanorod was equal to ca. $30 \mathrm{~nm}^{32}$. Zhang et al., used a novel electrochemical milling method to fabricate copper nanoparticles and nanofibers ${ }^{33}$. In another work, 
copper nanoparticles containing diamond-like carbon films were prepared on the Si substrate using electrochemical deposition method by choosing dimethylsulfoxide as carbon source and acetonitrile solution of $\left[\mathrm{Cu}\left(\mathrm{CH}_{3} \mathrm{CN}\right)_{4}\right] \mathrm{ClO}_{4}$ as dopant at relatively low voltage ${ }^{34}$. In two separate researches, copper nanoparticles were synthesized using copper sulphate by electrolysis method. They observed that the size of nanoparticles was about $40-60 \mathrm{~nm}^{35-36}$.

\section{Thermal decomposition}

Thermal decomposition is a chemical decomposition caused by heat. The decomposition temperature of a substance is the temperature at which the substance chemically decomposes [37]. Kim et al. synthesized copper nanoparticles by using thermal decomposition of Cu-oleate complex, which was prepared by the reaction with $\mathrm{CuCl} 2$ and sodium oleate in aqueous condition. TEM image showed well-dispersed copper nanoparticles with diameter of $8.9 \pm 1.3 \mathrm{~nm}$ [38]. In another work, copper oxalate was used as a precursor to prepare metallic copper nanoparticles by thermal decomposition. The size of nanoparticles was about $40 \mathrm{~nm}^{39}$. In 2014, synthesis of copper nanoparticles by thermal decomposition using copper chloride, sodium oleate, and phenyl ether as solvent agents was studied. TEM analysis showed spherical nanoparticles with sizes in the range of 4 to $18 \mathrm{~nm}$. In addition, they investigated the antibacterial activity of copper nanoparticles synthesized against strains of Staphylococcus aureus and Pseudomonas aeruginosa ${ }^{40}$.

\section{CONCLUSIONS}

Here, we described different approaches for fabricating copper nanoparticles using chemical methods. Chemical methods such as chemical reduction, photochemical, electrochemical, and thermal decomposition are used to synthesize copper nanoparticles and among them chemical reduction is the most frequently applied method for the preparation of stable, colloidal dispersions in organic solvents. Copper nanoparticles can easily oxidize to form copper oxide. Therefore, the reduction methods are usually performed under an inert atmosphere, in organic solvents or in presence of surfactants such as poly (vinyl pyrrolidone).

\section{REFERENCES}

1. Athanassiou, E. K.; Grass, R. N.; Stark, W. J. Nanotechnology. 2007, 17, 1668-1673

2. Moya, J. S.; Pecharroman, C.; Cubillo, A.; Montero, I. J. Am. Ceram. Soc. 2006, 89 (10), 3043-3049

3. Kang, X.; Mai, Z., Zou; X., Cai, P.; Mo, J. Anal. Biochem. 2007, 363, 143-150

4. Kantam, M. L.; Jaya, V. S.; Lakshmi, M. J.; Reddy, B. R.; Choudary, B. M.; Bhargava, S.K. Catal. Commun. 2007, 8, 1963-1968

5. Rodriguez, J. A.; Liu, P.; Hrbek, J.; Evans, J.; Perez, M. Angew. Chem. Int. Edit. 2007, 46, 1329-1332

6. Panigrah, S.; Kundu, S.; Ghosh, S. K.; Nath, S.; Praharaj, S.; Soumen, B.; Pal, T. Polyhedron. 2006, 25, 1263-1269

7. Nikhil, J.; Zhong, L. W.; Tapan, K. S.; Tarasankar, P. Curr. Sci. 2000, 79(9), 13671370

8. Zhong, C. J.; Mott, D.; Galkowski, J.; Wang, L.; Luo, J. Langmuir. 2007, 23, 5740-5745

9. Wang, C.Y.; Zhou, Y.; Chen, B.; Liu, H. J.; Mo,
X. J. Colloid. Interf. Sci. 1999, 220, 468-470

10. Wu, S. H.; Chen, D. H. J. Colloid. Interf. Sci. 2004, 273, 165-169

11. Park, B. K.; Jeong, S., Kim; D., Moon, J.; Lim, S.; Kim, J. S. J. Colloid. Interf. Sci. 2007, 311(2), 417-424

12. Song, X.Y.; Sun, S.X.; Zhang, W.M.;Yin, Z.L. J. Colloid. Interf. Sci. 2004, 273(2), 463-469

13. Su, X.D.; Zhao, J.Z.; Bala, H., Zhu;Y.C., Gao, Y.; Ma, S.S.; Wang, Z.C. J. Phys. Chem. C. 2007, 111(40), 14689-14693

14. Wu, C.; Mosher, B.P.; Zeng, T. J. Nanopart. Res. 2006, 8(6), 965-969

15. Zhu, H.T.; Lin, Y.S; Yin, Y.S. J. Colloid. Interf. Sci. 2004, 277(1), 100-103

16. Dang, T. M. D.; Le, T. T. T.; Fribourg-Blanc, E.; Dang, M. C. Adv. Nat. Sci. Nanosci. Nanotechnol. 2011, 2, 15-21

17. Park, B. K.; Jeong, S.; Kim, D.; Moon, J.; Lim, S.; Kim, J. S. J. Colloid. Interf. Sci. 2007, 311, 417-424

18. Salzemann, c.; Lisiecki, I.; Brioude, A.; Urban, 
j.; Pileni, M. P. J. Phys. Chem. B. 2004, 108(35), 13242-13248

19. Suramwar, N.V.; Thakare, S.R.; Khaty, N.T. Arab. J. Chem. 2012, DOI: 10.1016/ j.arabjc.2012.04.034

20. Ostaeva, G. Y.; Selishcheva, E. D.; Pautov, V. D.; Papisov, I. M. Polym. Sci. Ser. B. 2008, 50 (5-6), 147-149

21. Prucek, R.; Kvítek, L.; Panáek, A.; Vanurová, L.; Soukupová, J.; Janík, D.; ZboYil, R. J. Mater. Chem. 2009, 19, 8463-8469

22. Chatterjee, A. K.; Sarkar, R. K.; Chattopadhyay, A. P.; Aich, P.; Chakraborty, R.; Basu, T. Nanotechnology. 2012, 23(8), 85103-85113.

23. Malik, M. A.;Wani, M.Y.; Hashim, M. A.Arab. J. Chem. 2012, 5, 397-417

24. Qi, L.; Ma, J.; Shen, J. J. Colloid. Interf. Sci. 1997, 186(2), 498-500

25. Solanki, J. N.; Sengupta, R.; Murthy, Z. V. P. Solid State Sci. 2010, 12(9), 1560-1566

26. Kumar, A.; Saxena, A.; De, A.; Shankar, R.; Mozumdar, S. RSC Adv. 2013, 3, 5015-5021

27. Kaminskiene, Z.; Prosy£evas, I.; Stonkute, J.; Guobiene, A. Acta Phys. Pol. A. 2013, 123, 111-114

28. Condorelli, G. G.; Costanzo, L. L.; Fragalà, I. L.; Giuffridaa, S.;Ventimigliaa, G. J. Mater. Chem. 2003, 13, 2409-2411

29. Kapoor, S.; Mukherjee, T. Chem. Phys. lett.
2003, 370(1-2), 83-87

30. Giuffrida, S.; Costanzia, L. L.; Ventimiglia, G.; Bongiorno, C. J. Nanopart. Res. 2008, 10(7), 1183-1192

31. Zhu, X.; Wang, B.; Shi, F.; Nie, J. Langmuir. 2012, 28(40), 14461-14469

32. Yang, X.;Chen, S.; Zhao, S.; Li, D.; MA, H. J. Serb. Chem .Soc. 2003, 68(11), 843-847

33. Zhang, D. W.; Chen, C. H.; Zhang, J.; Ren, F. Chem. Mater. 2005, 17(21), 5242-5245

34. Huang, L.; Jiang, H.; Zhang, J.; Zhang, Z.; Zhang, P. Electrochem. Commun. 2006, 8(2), 262-266

35. Raja, M.; Subha, J.; Ali, F.B.; Ryu, S. H. Mater. Manu. Process. 2008, 23(8), 782-785

36. Theivasanthi, T.; Alagar, M. Ann. Bio. Res. 2011, 2(3), 368-373

37. Yu, S.H. J.Ceram. Soc. of Jpn. 2001, 109, 6575

38. Kim, Y. H.; Kang, Y. S.; Lee, W. J. Mol. Cryst. Liq. Cryst. 2006, 445, 231-238

39. Salavati-Niasari, M.; Davar, F.; Mir, N. Polyhedron. 2008, 27(17), 3514-3518

40. Betancourt-Galindo, R.; Reyes-Rodriguez, P. Y.; Puente-Urbina, B. A.; Avila-Orta, C. A.; Rodríguez-Fernández, O. S.; CadenasPliego, G.; Lira-Saldivar, R. H.; García-Cerda, L. A. J. Nanomater. 2014, Doi:10.1155/2014/ 980545 